\title{
Towards an improved understanding of farmers' behaviour: the integrative agent- centred (IAC) framework
}

Article

Accepted Version

Feola, G. and Binder, C. R. (2010) Towards an improved understanding of farmers' behaviour: the integrative agentcentred (IAC) framework. Ecological Economics, 69 (12). pp. 2323-2333. ISSN 0921-8009 doi:

https://doi.org/10.1016/j.ecolecon.2010.07.023 Available at https://centaur.reading.ac.uk/23997/

It is advisable to refer to the publisher's version if you intend to cite from the work. See Guidance on citing.

To link to this article DOI: http://dx.doi.org/10.1016/j.ecolecon.2010.07.023

Publisher: Elsevier

All outputs in CentAUR are protected by Intellectual Property Rights law, including copyright law. Copyright and IPR is retained by the creators or other copyright holders. Terms and conditions for use of this material are defined in the End User Agreement.

www.reading.ac.uk/centaur 
Central Archive at the University of Reading

Reading's research outputs online 


\title{
Towards an improved understanding of farmers' behaviour: The integrative agent-centred (IAC) framework.
}

\author{
Giuseppe Feola*1 ${ }^{1}$, Claudia R. Binder*§ \\ * Unit for Social and Industrial Ecology, Department of Geography, University of Zurich. Room 25J68, \\ Winterthurerstrasse 190, 8057 Zurich, Switzerland \\ ${ }^{\S}$ Institute of System Science, Innovation and Sustainability Research, University of Graz, Austria \\ ${ }^{1}$ (corresponding author): Tel +41 (0)44 6355232; Fax +41 (0)44 6356848; giuseppe.feola@geo.uzh.ch
}

\begin{abstract}
An effective approach to research on farmers' behaviour is based on: i) an explicit and well motivated behavioural theory; ii) an integrative approach; iii) understanding feedback processes and dynamics. While current approaches may effectively tackle some of them, they often fail to combine them together. The paper presents the integrative agent-centred (IAC) framework, which aims at filling this gap. It functions in accordance with these three pillars and provides a conceptual structure to understand farmers' behaviour in agricultural systems. The IAC framework is agent-centred and supports the understanding of farmers' behavior consistently with the perspective of agricultural systems as complex Social-Ecological Systems. It combines different behavioural drivers, bridges between micro and macro levels, and depicts a potentially varied model of human agency. The use of the framework in practice is illustrated through two studies on pesticide use among smallholders in Colombia. The examples show how the framework can be implemented to derive policy implications to foster a transition towards more sustainable agricultural practices. The paper finally suggests that the framework can support different research designs for the study of agents' behaviour in agricultural and social-ecological systems
\end{abstract}




\section{Introduction}

Achieving a sustainable agriculture is a one of the most important goals for the near future (Unced, 1992; Conway, 1998, p.33; WSSD, 2002; FAO, 2002). Unsustainable production practices are causing water scarcity, soil erosion, loss of biodiversity and pest resistance to pesticides, among other environmental problems, in many agricultural systems worldwide (Ruttan, 1999). Furthermore, the depletion of the ecosystem's health and services is often intertwined with health, food security and poverty issues, especially in the most marginal rural areas in developing countries (Rigby and Caceres, 1997; Tait and Morris, 2000; Altieri, 2002; Thompson et al., 2007).

In order to foster the transition of agricultural systems towards more sustainable agricultural practices, i.e. a technological, cultural, institutional, and normative reconfiguration of the system (Rotmans et al., 2001; Geels and Schot, 2007; Smith and Stirling, 2008), intervention strategies and an appropriate governance of agricultural systems need to be implemented at different institutional and spatial levels (Altieri, 2002; Rammel et al., 2004 and 2007; Thompson et al., 2007).

The effectiveness of such strategies depends mainly on two aspects. First, agricultural systems need to be conceptualized as complex, multi-scale and multi-level systems (Dent et al., 1995; Berger et al., 2006; Thompson et al., 2007; Darnhofer et al., 2008). Second, a thorough understanding of farmers' behaviour ${ }^{1}$ has to be achieved, farmers being the key actors within these systems (Öhlmer et al., 1998; Webster, 1999; McGregor et al., 2001; Edwards-Jones, 2006).

Agricultural systems are Social-Ecological Systems (SES) characterized by two interlinked and interdependent subsystems, i.e. a socio-system and an eco-system, co-evolving and interacting at various levels and scales (Norgaard, 1984; Woodhill and Röling, 1998; Matthews and Selman, 2006; Thompson et al., 2007; Darnhofer et al., 2008). Consequently, agricultural systems are characterized by "non-equilibrium, dynamics, spatial, temporal and cultural variation, complexity and uncertainty" (Thompson et al., 2007). In such systems, sustainability itself should be regarded as a process in (temporary) equilibrium, and not as a permanent system state.

As argued also for other kinds of SES (Rammel et al., 2007), deterministic governance approaches are unlikely to be successful in pursuing sustainability because they do not recognize the inherent uncertainty characterizing complex systems, the importance of different scales and levels at which key processes occur, and the existence of different knowledge systems (Leach et al., 2007, Rammel et al., 2004 and 2007; Thompson et al., 2007;). Similarly, panaceas, i.e. one-for-all solutions or universal remedies, do not recognize the context-specificity of SES and the diversity of individual motives, agents' preferences and perceptions and, most importantly, social structures in the system (Ostrom et al., 2007).

In this context, instead of providing solutions to achieve equilibrium states or single, static predictions based on current understanding of future conditions, research is called for to develop insights into how a specific system, both in its ecological and social components, might respond to internal and external sources of change in order to assess different potential transition pathways towards sustainability (Park and Seaton, 1996; Parker et al., 2001;

\footnotetext{
${ }^{1}$ The term "behaviour" refers in this paper to an action or a series of actions. An "action", or "social action", refers to a series of acts enacted by a social actor, selected among possible alternatives, on the basis of a plan which can evolve in the course of the action itself. The social action aims at a goal, given a situation or context shared also by other actors who can react, and by norms, values, means, and physical objects, which the actor considers, to the extent he/she disposes of information and knowledge (adapted from Gallino, 1993). "Social action" and "behaviour" are distinguished from "decision-making", which refers to the cognitive "process of making a selective intellectual judgment when presented with several complex alternatives consisting of several variables, and usually defining a course of action or an idea" (from the Online Medical Dictionary: http://www.mondofacto.com/dictionary/).
} 
Belcher et al., 2004; Rammel et al., 2007; Scoones et al., 2007). It is on the understanding of ecological and social dynamics and the reciprocal influences between them that effective strategies to foster sustainability transitions in agricultural systems depend.

While there is now growing agreement on the conceptualization of agricultural systems as SES and its implications for research (e.g. Norgaard, 1984; Thompson et al., 2007; Rammel et al., 2007), more work has been called for with regard to farmers' behaviour and its understanding in relation to the complexity of agricultural systems (e.g. Norgaard, 1984; Parker et al., 2001; Janssen and Ostrom, 2006; Darnhofer, et al., 2008).

The present paper aims at filling this gap by proposing the integrative agent-centred (IAC) framework, a conceptual tool for improving the understanding of farmers' behaviour. By helping to develop insights into behavioural dynamics more than states, its application can support the governance of sustainability transition processes.

The paper is structured as follows. First, the requirements for an effective approach to research on farmers' behaviour in agricultural systems are presented and a short overview of the literature in the field is given. In particular, three main requirements are identified. Second, the theoretical background and the components of the IAC framework are described. It is shown how the framework can fulfill the three identified requirements. Third, the usefulness of the framework is then illustrated through examples. A particular emphasis is posed on the policy implications which can be derived though the application of the IAC framework. Finally, caveats and further applications of the framework are discussed.

\section{Requirements for an effective approach to research on farmers' behaviour in agricultural systems}

The effectiveness of strategies for governing agricultural systems depend on a thorough understanding of farmers' behaviour, as farmers are the key actors within these systems (Öhlmer et al., 1998; Webster, 1999; McGregor et al., 2001; Edwards-Jones, 2006). Recent research developments in the fields of human decision-making and of agricultural systems and SES suggest that an effective approach to farmers' behaviour is based on three main requirements, which are discussed in this section:

i) an explicit and well-motivated behavioural theory;

ii) an integrative approach;

iii) the understanding of feedback processes and dynamics.

\subsection{Behavioural theory}

An explicit and well-motivated behavioural theory is considered essential to investigate agents' behaviour and its relationship with system dynamics (Parker et al., 2001; Janssen and Ostrom, 2006; Matthews and Selman, 2006). The theory should provide solid assumptions about micro-level behavioural dynamics on which to base policy recommendations to increase policy effectiveness (Jager and Janssen, 2002). The theory should not only guide selection of aspects to be considered in the analysis (i.e. potential explanatory factors) but also, importantly, the identification of the relationships among them, to be verified for each specific case study, in order to support context-specific strategies needed to cope with the complexity of SES (van den Bergh et al., 2000; Rammel et al., 2004 and 2007; Bolte et al., 2006; Matthews and Selman, 2006; Galt, 2008).

Research on farmers' behaviour has in some cases adopted behavioural theories from the social sciences (e.g. Willock et al., 1999; Burton, 2004). Examples of this approach are related to the application of the Theory of Reasoned Action and the Theory of Planned Behaviour (Ajzen, 1991; Fishbein and Ajzen, 1975; Burton, 2004) to pesticide use (Heong and Escalada, 1999) and to agro-forestry practices (Zubair and Garforth, 2006). 
However, significant strands of research in the field do not rely on an explicit and wellmotivated behavioural theory. Thus, for example, in many econometric studies investigating the determinants of farmers' efficiency in resource use, the explanatory variables are drawn from previous studies, in general do not refer to a consistent theoretical framework, and their choice is usually not justified (e.g. Dung and Dung, 2003; Dasgupta et al., 2007). This is also the case for many studies investigating pesticide use (e.g. Chaves and Riley, 2001; Rahman, 2003; Galt, 2008). Similarly, in simulation modelling the agents' decision-making rules are either empirically defined (e.g. through storylines), or only weakly based on often reductionist behavioural theories (e.g. Krebs et al., 2007; Happe et al., 2006; Merot et al., 2008).

Thus, as noted for example by Irwin and Geoghegan (2001) with reference to land use studies, there is a risk of having models that claim to represent human behaviour which are not explicitly and solidly grounded in theories of human behaviour.

\subsection{Integrative approach}

While necessary, a behavioural theory is not sufficient to provide a solid basis for the investigation of farmers' behaviour if it does not allow for integrating, first, the social and ecological system's components and, second, different types of human agency.

Integration between natural and social domains is considered essential if human-driven, complex, nonlinear dynamic processes and patterns are to be investigated in SES (e.g. Costanza et al., 1993; Peterson, 2000; Liu, 2001; Folke, 2003; Redman et al., 2004; Liu et al., 2007) and in particular in agricultural systems (e.g. Park and Seaton, 1996; Oriade and Dillon, 1997; Rossing et al., 2007; Galt, 2008). In this sense, it is acknowledged that human behaviour often functions as a bridge between the social and ecological subsystems of a SES. Thus, integration is considered the only approach which allows for investigating issues such as feedback processes, transitions, nonlinear dynamics, and exploring the existence and effects of thresholds, time-lags and heterogeneity in the system (Liu et al., 2007).

Integration is also considered essential in investigating agents' behaviour. In this case, integration refers to melding different insights, i.e. from different disciplines such as economics and socio-psychology (Edwards-Jones, 2006). In doing so, integration challenges reductionist approaches such as the model of Homo oeconomicus, which has long dominated research, despite been discredited in the social sciences as an oversimplified model of human agency (Rabin, 1998; Kahnemann and Tversky, 2000; Jackson, 2004), and which is especially misleading for studying human-environment interactions (Janssen and Jager, 2000). In order to overcome reductionism and therefore to accommodate different types of social actor, Parker et al. (2001), for example, suggest relying on a flexible and integrative model, which could allow for weighted inputs from different strategies that may change depending on the specific situation or decision.

Integrative approaches to studying farmers' behaviour are seldom seen in practice (EdwardsJones, 2006). Research has been widely based, implicitly or explicitly, on the assumption that farmers are rational profit maximizers (McGregor et al., 2001; Edwards-Jones, 2006). This assumption is often retained, for example, in the most recent developments in simulation modelling (e.g. Berger, 2001; Sharma et al., 2006; Belcher et al., 2004; Berger et al., 2006; Happe et al., 2006, Noailly, 2008).

Despite the predominance of the rational man assumption, farmers' behaviour has also been tackled through other theoretical and methodological approaches. For example, regarding the issue of pesticide use, advances have been made by addressing culture (e.g. Gurung, 2003; Palis et al., 2006), social norms (e.g. Heong and Escalada, 1999; Heong et al., 2002), the social context (e.g. Nkamleu and Adesina, 2002), imitation of peers (Schmit and Rounsevell, 2006), attitudes and perceptions (Zubair and Garforth, 2006) and the role of specific contingencies which might influence farmers in an action context, e.g. inadequate risk communication (e.g. Waichmann et al., 2007). 
Although the individual strands of research have brought interesting contributions to the understanding of farmers' behaviour, there is reason to believe that an integration of different perspectives can yield higher research results for investigating transition processes in the context of SES (Galt, 2008). As argued by Geels and Schot (2007), "detailed case studies have shown that most transitions involve multiple types of agency and causal processes that may alternate". Therefore, the relative significance of different potentially relevant factors in explaining agents' actions in varying contexts has to be tested (Edwards-Jones, 2006; Galt, 2008), which requires moving from one-dimensional explanations to the systematic integration of different potentially relevant behavioural factors.

\subsection{Feedback processes and dynamics}

Feedback processes are typical of SES (e.g. Costanza et al., 1993; Liu et al., 2007). While the contribution of individual actions to processes occurring at the macro level has received significant attention, understanding how feedback processes from the macro- to the individual level (e.g. social norms) may influence farmers' actions is still considered an open issue for the understanding of dynamics in agricultural systems (Norgaard 1984; Parker et al., 2001; Thompson et al., 2007) and more in generally in SES (Scoones, 1999; Manson, 2001; Scoones et al., 2007; Waring, in press).

By integrating feedback processes and dynamics into research on farmers' behaviour, it is possible to avoid static, constant-cause explanations (Geels and Schot, 2007), which represent a relevant body of research in the field, despite the growing diffusion of other approaches, such as simulation models which acknowledge the co-evolutionary and complex nature of agricultural systems (e.g. Munro, 1997; Sharma et al., 2006; Happe et al, 2006; Noailly, 2008). Static explanations may prove of little use in understanding either agents' behaviour or the reciprocal influences between individual action and the agricultural system. In effect, it has been shown that the behavioural drivers may themselves change over time. For instance, Lichtenberg and Zimmerman (1999) showed that farmers who experienced adverse health effects due to pesticide use were more likely to change their behaviour, i.e. to adopt safety measures in managing pesticides. These findings established the existence of specific mechanisms of farmers' learning from past behaviour, of adaptation to conditions which had changed because of their own actions, and possibly of innovation, in finding new practices and ways of managing risk.

Therefore, it is by considering the feedbacks between individual behaviours and the system dynamics that it is possible to understand how institutional innovation arises and can be maintained, especially in relation to potentially adverse contextual conditions (Braun et al., 2006; Matthews and Selman, 2006) such as those many agricultural system and marginal rural areas are facing. That is, what is key is to explore transition pathways and possibilities for temporary stabilization of more sustainable system configurations.

In summary, the nature of agricultural systems as SES requires the investigation of farmers' behaviour on the basis of three pillars: i) an explicit and well-motivated behavioural theory; ii) an integrative approach; iii) feedback processes and dynamics. However, while current approaches may effectively tackle some of them, they often fail to combine the three pillars. This paper presents the integrative agent-centred framework, which aims at filling this gap. The next sections show how the integrative agent-centred (IAC) framework can

i) combine the three requirements, and

ii) be implemented to provide an improved understanding of farmers' behaviour. 


\section{The integrative agent-centred framework}

\subsection{Theoretical background}

The integrative agent-centred (IAC) framework is rooted in the action-theoretic approach to social research. According to this approach, a social phenomenon has to be analysed as the product of individual actions which, in turn, are an adaptive function of the social situation's structure, i.e. the macro-social physical and symbolic context in which the actor is embedded (Boudon, 1985, p.44). Consequently, the social action represents the understandable unit of research, i.e. the actor's motivation for an action in a specific situation, and not the macrophenomena which result from the aggregation of individual actions (Weber, 1978). The researcher can interpretively understand (verstehen) the meaning of the action for the actor in his/her situation, i.e. its adaptive value, through detachment, collection of information and social investigation based on an ideally diverse set of research tools (Boudon, 1985, p.69).

The IAC framework provides a conceptual structure for such an interpretive understanding of farmers' action in its specific structural context. The components of the framework are based on the integration of the Structuration Theory (Giddens, 1984) and the Theory of Interpersonal Behaviour (Triandis, 1980).

3.1.1 Structuration Theory. Giddens' Structuration Theory (ST) (Giddens, 1984) unifies the micro- (social actor) and macro- (structure) levels, that is, individuals' contribution to social structure reproduction and, in turn, social structures' influence on individual actions. According to ST, actors influence, and at the same time are influenced by, social structures (duality of structure). Thus, ST allows overcoming the reductionist approach to social systems by conceptualizing a recursive social reproduction, which corresponds to what is called circular causality in complex adaptive systems such as SES (Fuchs, 2003; Janssen and Ostrom, 2006).

ST is actor-centred. Social structures exist only in human activities and are reproduced or changed through the feedbacks called reflexive self-regulation, for intended consequences, and homeostatic loop, for consequences which are unintended but nevertheless change the conditions of action in the future (Giddens, 1984). Actors' reflexivity also implies creativity, as social actors do not simply respond to changes in the structures, but may design new ones, i.e. innovate (Gual and Norgaard, in press). Furthermore, as actors are situated in space and time and in specific configurations of rules and resources (Giddens, 1984) the spatio-temporal context takes on a fundamental relevance in determining social reproduction (Fuchs, 2003; Thompson et al., 2007).

Because the actors lie within the system, the social system is a self-modifying or selforganizing system (Mayumi and Giampietro, 2006), where change emerges from the action of a multitude and variety of individuals. Therefore, change does not have to be linear or to result in societal progress, but, on the contrary, it is likely to be discontinuous, non-linear and with multiple alternative equilibria (Fuchs, 2003; Thompson et al., 2007). Finally, it has been argued that ST is useful for the understanding of the dynamic interactions between levels in human-environment systems (Scoones, 1999; Thompson et al., 2007; Geels and Schot, 2007; Binder et al., 2004; Binder, 2007).

One of the criticisms that has been leveled at ST concerns the fact that it is rather general and therefore difficult to apply to empirical research (Archer, 1990). In particular, while ST emphasises the importance of a rule-based, purposive agent, the decision-making structures of the agents themselves are not specified, which leaves room for different conceptualizations of agency (Geels and Schot, 2007).

3.1.2 Theory of Interpersonal Behaviour. Triandis' Theory of Interpersonal Behaviour (TIB) (1980) is a psychological theoretical framework which aims at explaining individuals' 
"interpersonal" behaviour. In TIB, intentions, habit, physiological arousal and contextual factors influence the present behaviour of the agent. Furthermore, intentions are themselves determined by normative, cognitive and affective antecedents. This theoretical framework provides a way to overcome most of the criticism directed at rational choice theory, offering a comprehensive heuristic as well as a model for empirical analysis of the "strengths and weaknesses of different component factors in different kinds situations" (Jackson 2004).

TIB has been applied to various issues, including environmentally relevant behaviour (Thompson et al., 1991; Boots and Treolar, 2000; Bamberg and Schmidt, 2003; Gagnon et al., 2003) and has generally shown a higher explanatory power than competing behavioural theories. In addition, TIB is more comprehensive than other theories (Jackson, 2004) in that it includes a wide array of potentially relevant drivers, which makes it appropriate to the integrative investigation of agents' behaviour in complex systems, as called for, for example, by Scoones et al. (2007) and, with specific reference to farmers' decision-making, by Edwards-Jones (2006).

In the context of application to agents' behaviour in complex agricultural systems, the TIB has two main limits. First, the link between micro and macro-level, and in particular the process of emergence of social phenomena is weakly considered. Secondly, the recurrence of social reproduction is weakly developed. The TIB does not consider feedback, despite this being partially present in the concept of reinterpretation, i.e. the agent interprets the consequences of his/her actions and consequently modifies his/her expectations for the future. Thus, for example, although culture and values are potential drivers of agents' action, their social reproduction by human activities is not a focus of the TIB.

The ST and the TIB are compatible and consistent. Moreover, the combination of the two theories allows for an improved approach to agents' behaviour by framing the feedback processes occurring between the agent and the system. Both are agent-centred and conceptualize the agent as purposive, endowed with bounded-rationality, and reflexive, i.e. the agent controls the results of his/her actions and, by re-interpreting them, may change expectations and behavioural choices in the future. Furthermore, the issues of micro-macro level interactions and recurrence, which are weakly developed in the TIB, are addressed by the ST. On the other hand, the TIB provides a structure of behavioural drivers which can complement the ST in its application in empirical research. In particular, it provides greater detail on how resources and rules may be configured concretely and thus influence the action of the social agent.

\subsection{The components of the IAC framework}

As discussed above, in the IAC framework behaviour (B), which may differ for example in frequency, probability of occurrence, intensity and duration, is determined by contextual (external) factors as well as internal ones (Equation 1).

$$
\mathrm{B}=f\left(\mathrm{~F}_{\mathrm{i}}, \mathrm{H}, \mathrm{I}, \mathrm{P} ; \mathrm{w}_{\mathrm{F}}, \mathrm{w}_{\mathrm{H}}, \mathrm{w}_{\mathrm{I}}, \mathrm{w}_{\mathrm{P}}\right)
$$

$$
\begin{aligned}
& \text { Where: } \\
& \begin{array}{ll}
\mathrm{B} & =\text { behaviour; } \\
\mathrm{F}_{\mathrm{i}} & =\text { contextual factor } \mathrm{i} ; \\
\mathrm{H} & =\text { habit of performing the act; } \\
\mathrm{I} & =\text { behavioural intention; } \\
\mathrm{P} & =\text { physiological arousal; } \\
\mathrm{W}_{\mathrm{F}}, \mathrm{W}_{\mathrm{H}}, \mathrm{W}_{\mathrm{I}}, \mathrm{W}_{\mathrm{P}} & =\text { weightings for contextual factors, habit, intention and } \\
& \text { physiological arousal. }
\end{array}
\end{aligned}
$$


The contextual factors $\left(\mathrm{F}_{\mathrm{i}}\right)$ are "objective factors, "out there" in the environment" (Triandis, 1980). They can make an act easy (facilitating conditions) or difficult (barriers) to carry out. They can be differentiated into socio-economic, agro-ecological and political (Galt, 2008). Environmental characteristics of the system, the social context of the agent, the processes occurring in the agricultural system (e.g. increasing pest resistance to pesticides, climatic conditions), as well as the authoritative (e.g. power relationships) and allocative (e.g. financial capital) resources (Giddens, 1984) are all examples of aspects considered among the contextual factors in the framework.

Habits $(\mathrm{H})$ are "situation-behaviour sequences that are or have become automatic, so that they occur without self-instruction" (Triandis, 1980). Habit describes the level of routinisation of the behaviour.

The degree of physiological arousal (P), the physiological state of the individual, may also be considered (Triandis, 1980). It "can be zero when the individual is asleep and 1.00 when the individual is extremely aroused" (Triandis, 1980). This factor may be particularly important in tactical decisions, as opposed to strategic plans.

Finally, intentions (I) are "instructions that people give to themselves to behave in certain ways" (Triandis, 1980). In the IAC framework, Intention is determined by an agent's subjective culture (S), affect (A) and expectations about the act (E) (Equation 2).

$$
\mathrm{I}=f\left(\mathrm{~S}_{\mathrm{k}}, \mathrm{A}, \mathrm{E}_{\mathrm{j}} ; \mathrm{w}_{\mathrm{S}}, \mathrm{w}_{\mathrm{A}}, \mathrm{w}_{\mathrm{E}}\right)
$$

$\begin{array}{ll}\text { Where: } & \text { = behavioural intention; } \\ \mathrm{S}_{\mathrm{k}} & =\text { subjective culture with sub-components } \mathrm{k} ; \\ \mathrm{A} & =\text { affect attached to the behaviour; } \\ \mathrm{E}_{\mathrm{j}} & =\text { expectations } \mathrm{j} ; \\ \mathrm{W}_{\mathrm{S}}, \mathrm{w}_{\mathrm{A}}, \mathrm{w}_{\mathrm{E}} & =\text { weightings for subjective culture, affect and expectations. }\end{array}$

Subjective culture (S) "refers to a human group's characteristic way of viewing the humanmade part of the environment" and "consists of ways of categorizing experience" (Triandis, 1980). The attribute subjective underlines that the fact that social structures only exist in each agent. In the framework, the subjective culture is a product of three main components: social norms, roles and values.

Social norms are "what is perceived to be correct and appropriate by members of a culture in certain situations" (Triandis, 1980). Social norms have a legitimating function, as they define the set of moral rules valid in a certain social system (Giddens, 1984). In the framework, social norms are categorised as prescriptive or descriptive. The former are codified prescriptions indicating to the members of a culture the appropriate behaviour under certain circumstances, resources and personal characteristics. They can be formalized in the legislation or not (adapted from Gallino, 1993). The latter are the behaviour that is observed with the highest frequency in a population exposed to a certain situation (adapted from Gallino, 1993). Examples of prescriptive social norms are the norms for accessing water resources in a basin (which may be formalized or not) and the reference groups' opinion (informal). The descriptive norm is defined by other farmers' behaviour. In addition, the sense of compliance with the social norms is considered in the framework as a measure of their strength for the agent.

Roles are "behaviours appropriate for a person holding a particular position in a group, society or social system" (Triandis, 1980). For example, in a strictly patriarchal and hierarchical social system, not only the role of farmer, but also that of head of family may be 
additionally considered. In addition, the sense of compliance with the roles is considered in the framework as a measure of their strength for the agent.

Values are defined as "relationships among abstract categories with strong affective components, implying a preference for a certain kind of action" (Triandis 1980). Values are culturally determined and personally interpreted by the agent. They have a signification function (Giddens, 1984); that is, they help the agent by giving meaning to situations and thus being relevant for the interpretation of outcomes and the selection of goals (Triandis, 1980).

Affect (A) refers to the emotional system of an individual, i.e. "the feelings associated by an individual with a particular act" (Triandis, 1980).

Expectations (E) correspond to the expected consequences of the act, their probability of occurrence and their value (Triandis, 1980). For example, health problems due to the use of chemical inputs and the related cost, or yield and income are examples of expectations.

Finally, the weightings to be attributed to the different components of the IAC framework are not fixed values. They underline the fact that the strength of each component may change depending on the decision, the agent and the situation analyzed. This allows for accounting for different types of agencies, and for agencies changing over time. Thus, for example, an ideal-typical profit-maximizing farmer would be characterized by a null value of $\mathrm{w}_{\mathrm{F}}, \mathrm{w}_{\mathrm{H}}, \mathrm{w}_{\mathrm{I}}$, $\mathrm{w}_{\mathrm{P}}, \mathrm{w}_{\mathrm{A}}$, and $\mathrm{w}_{\mathrm{S}}$, so that his decision would be dominated by expectations. In contrast, the action of an ideal-typical Homo sociologicus (Dahrendorf, 2006), would be explained by the component subjective culture.

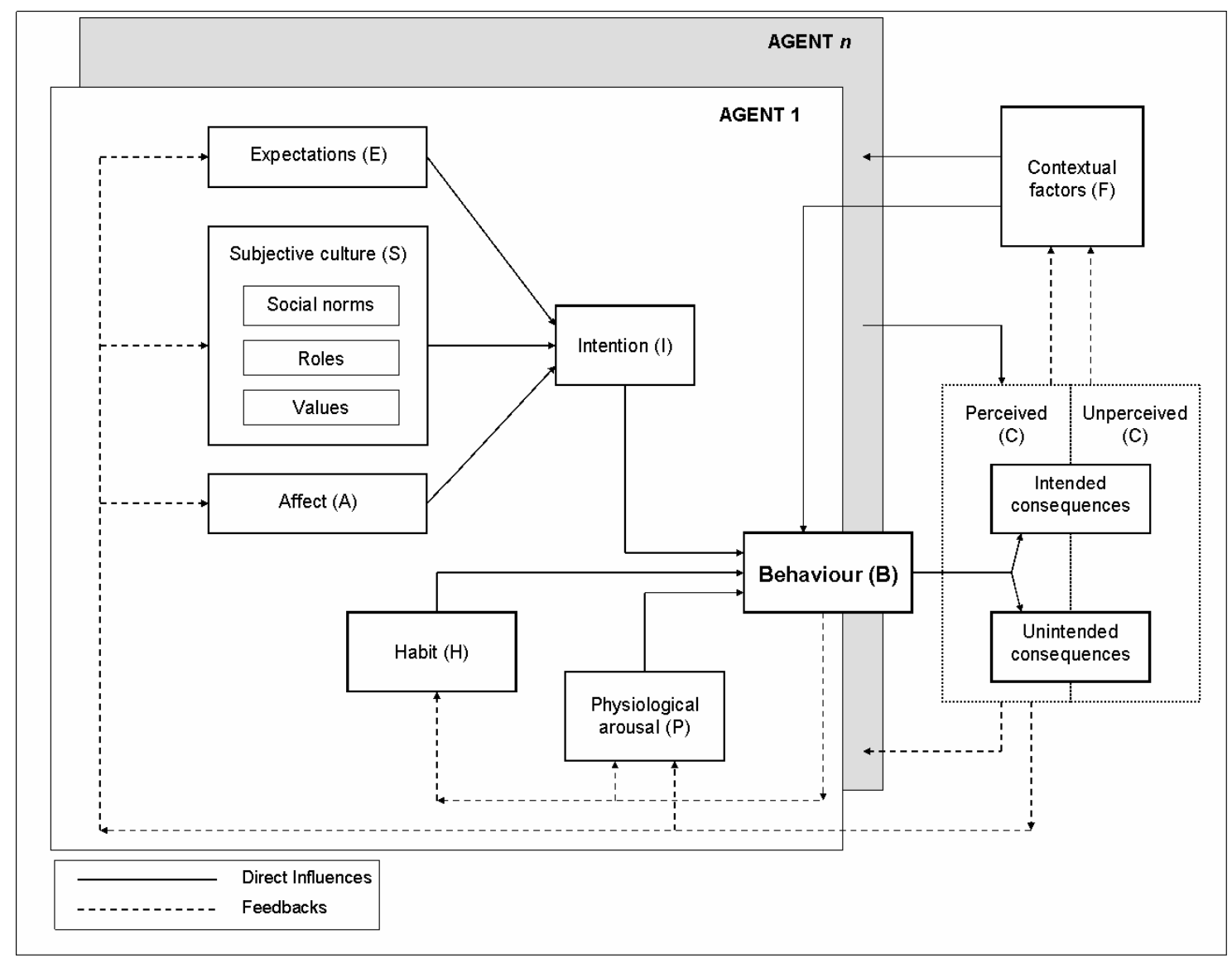

Figure 1. Representation of the integrative agent-centred (IAC) framework.

Figure 1 represents the IAC framework. As mentioned above, agents' behaviour can be explained based on intention (I), habit $(\mathrm{H})$, physiological arousal $(\mathrm{P})$ and contextual factors (F). This decision has intended or unintended and perceived or unperceived consequences (C). 
The consequences feed back to the farmers through changes in the contextual factors (homeostatic loop, Giddens 1984). Only the perceived consequences which are reinterpreted by the agent (Triandis, 1980) feed back directly to farmers by influencing intention, affect, habit and physiological arousal (reflexive self-regulation, Giddens 1984).

The feedback processes can reinforce the current state or trigger change, and can occur at different temporal levels. Feedbacks involving expectations, affect or physiological arousal, for example, are likely to be relatively short-term, while those involving subjective culture and habit are more likely to be long-term.

Agents' interactions occur either directly or indirectly. The former depend on the agents' network (e.g. extension, density, heterogeneity). The latter occur through the consequences of behaviour, which can aggregate at the next higher hierarchical level, being perceived and reinterpreted by individual agents. For instance, pest resistance, prices of agricultural products on the market and social norms are all aggregated effects of individual actions.

\section{The IAC framework in use: pesticide use among smallholders in Colombia}

Feola and Binder (2010a; 2010b) applied the IAC framework to the study of pesticide use among smallholder potato producers in Boyacá, on the Colombian Andes. In this section, the study design, results and policy implications are outlined, to illustrate the application of the IAC framework to this case. More detailed information is to be found in Feola and Binder (2010a; 2010b).

\subsection{Problem and goals of the studies}

Health, environmental and economic adverse effects of pesticide use have been observed among smallholder potato producers in the area of Boyacá, Colombia. The level of use of personal protective equipment (PPE) is generally low and farmers frequently suffer from pesticide-related symptoms (Ospina et al., 2008; Schöll and Binder, 2009; Feola and Binder, 2010a). Signs of environmental effects are also observed, e.g. loss of biodiversity in the soil (Schöll and Binder, 2009). In addition, farmers' crop protection products represent around $14 \%$ of the production costs for smallholders (Gobernación de Boyacá Dirección de Desarrollo Agropecuario, 2004), which is considered a sign of problematic pest control tactics.

Thus, while previous studies have raised the issue of unsustainable pesticide and PPE use, the main goal of the study was to investigate the behavioural determinants and suggest policy options to foster a transition towards a more sustainable pesticide use.

The framework was applied to the investigation of two distinct behaviours, namely the use of PPE during the application of pesticides (Feola and Binder, 2010a), and the adoption of different pesticide application patterns (Feola and Binder, 2010b) respectively.

\subsection{Procedure.}

The studies' research design entailed the translation of the general equations (1) and (2) into statistical models to explain the studied behaviours. First, the general components of the IAC framework were associated to the variables which were potentially influencing the studied behaviours (Figure 3, step a). This entailed a literature review and interviews with the farmers. Through the former, the potential behavioural drivers and processes found to be influencing pesticide use in the literature were identified, and then associated to one of the components of the IAC framework (e.g. cost of the protective equipment to expectations, and social norms to the subjective culture). The latter, i.e. the interview with the farmers, helped to point out potential additional behavioural drivers which were specific of the study area of Boyacá (e.g. specific social network). These additional drivers were also associated with the 
components of the IAC framework. As an example, the list of variables, i.e. behavioural drivers, considered for the behaviour use of PPE is showed in Table 1.

Table 1. Example of variables considered for the behaviour use of PPE.

\begin{tabular}{|c|c|}
\hline $\begin{array}{c}\text { Components of the IAC } \\
\text { framework }\end{array}$ & Behavioural drivers (variables) \\
\hline Behaviour & Frequency of use of Personal Protective Equipment (PPE). \\
\hline Social norms & $\begin{array}{l}\text { (i) Prescriptive: legislation, pesticide safety labels, reference groups' } \\
\text { opinion; (ii) Descriptive: other farmers' behaviour; (iii) Sense of } \\
\text { compliance with the social norms. }\end{array}$ \\
\hline Roles & (i) Farmer, head of family; (ii) Sense of compliance with the roles. \\
\hline Affect & Emotions associated with the use of a certain PPE. \\
\hline Habit & Years using a certain PPE. \\
\hline Contextual factors & $\begin{array}{l}\text { (i) Share of pesticide-related work; (ii) Experience of pesticide-related } \\
\text { health problems; (iii) Knowledge/Skills; (iv) Wealth; (v) Weather. }\end{array}$ \\
\hline $\begin{array}{l}\text { Consequences and } \\
\text { Expectations and their } \\
\text { value }\end{array}$ & $\begin{array}{l}\text { (i) Health (i.e. health problems of farmer, health problems of farmer's } \\
\text { family); (ii) Social (i.e. social judgment about working wearing PPE); } \\
\text { (iii) Technical (i.e. difficulty in working wearing PPE); iv) Cost of PPE; } \\
\text { v) Cost of doctors; vi) Cost of medications; vii) Work days lost. }\end{array}$ \\
\hline
\end{tabular}

The variables were then operationalized to be measured through a structured questionnaire (Feola and Binder, 2010a; 2010b) (Figure 3, step b). For example, the legislation was operationalized into knowledge of existing laws on pesticide use and degree of compliance with such laws.

The data were collected through a structured questionnaire based on the IAC framework (Figure 3, step c). Different types of questions were used in the questionnaire, such as open and closed questions, multiple-option and scales. The questionnaire (Feola, 2010) was structured in sections, each section corresponding to a component and containing one or more questions for each variable (Figure 2). 


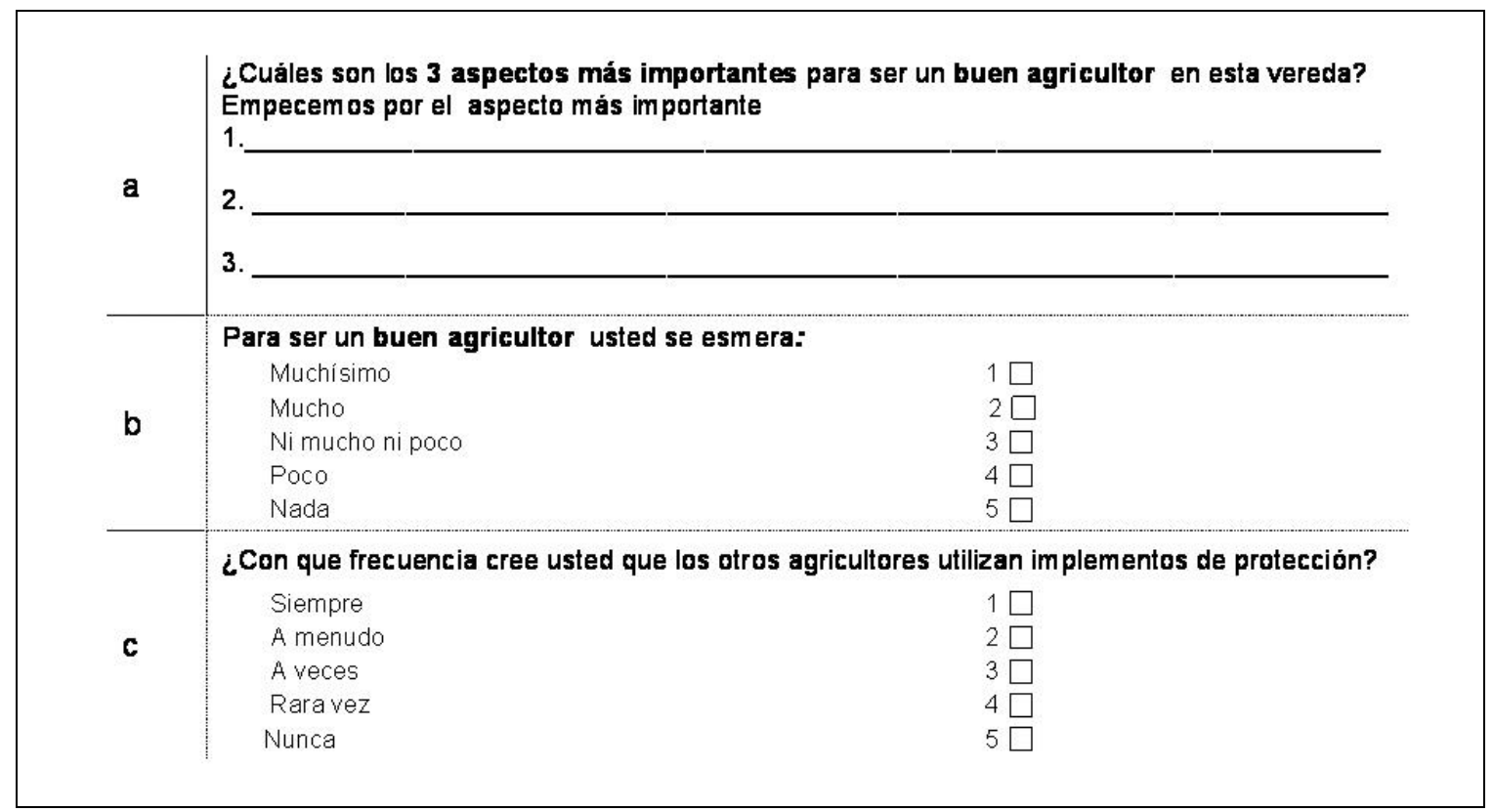

Figure 2. Examples of questions posed in the survey: a) social definition of the role of farmer; b) sense of compliance to the social role of farmer; c) descriptive social norm use of personal protective equipment.

A survey was conducted in September and October 2007, involving a total of 197 smallholder potato growers in four communities in the area of Boyacá, Colombia. Data concerning PPE and pesticide use were collected together.

The IAC framework also drove the data analysis (Figure 3, step d). First, for each farmer, a characterization of the PPE use and pesticide use patterns was carried out, in terms of frequency of PPE use and features of pesticide use patterns such as intensity, frequency of application, and chemical classes applied. Second, the influences of the different behavioural drivers on i) PPE use and ii) adoption of pesticide application pattern were investigated. Concerning PPE use, the attributes of the behaviour investigated (component B in equation (1)) were probability and frequency of use respectively. Concerning pesticide use, the attribute investigated was the probability of adopting a given pesticide application type. Therefore, the use of PPE and the adoption of the pesticide application pattern respectively were defined in probabilistic terms, which entailed the specification of equations (1) and (2) into standard binomial (for PPE use) and multinomial logistic regression equations (for pesticide use). Consequently, the coefficients, i.e. w components in equations (1) and (2), were estimated statistically through the regression procedures. This permitted to quantify the influences and feedbacks which were initially hypothesized as being relevant for farmers in the study area, and test their significance. Details of the estimated equations can be found in Feola and Binder (2010a; 2010b). 


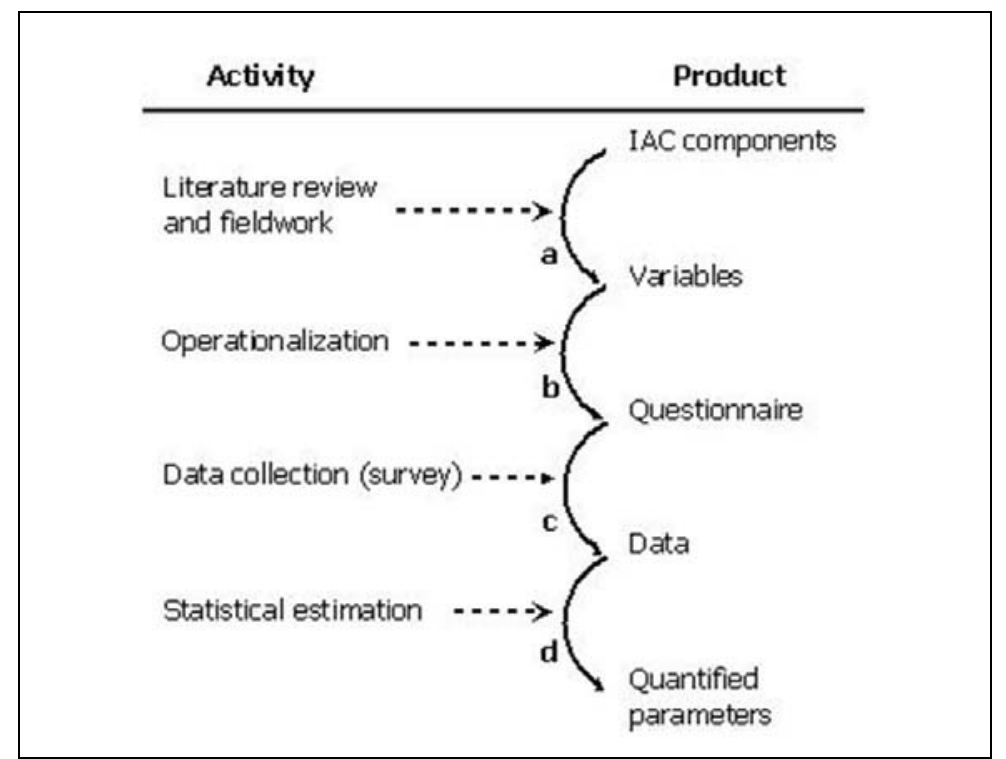

Figure 3. Parameterization procedure of the IAC framework's components.

\subsection{Results.}

The results for both studies, i.e. PPE and pesticide use, confirm the usefulness of the IAC framework to combine the three pillars which are required to investigate farmers' behaviour in agricultural systems, i.e. i) an explicit and well-motivated behavioural theory; ii) an integrative approach; iii) feedback processes and dynamics.

4.3.1. Behavioural theory. The IAC framework functioned as a heuristic, which allowed for positioning the agents in their system and identifying the potential factors and processes characterizing the system which had to be included in the analysis. This represents an improvement over other current approaches, which tend either not to be theoretically grounded or, if theoretical, to rely on a reductionist, and therefore oversimplified, behavioural model (Edwards-Jones, 2006; Matthews and Selman, 2006).

Accordingly, the IAC framework also allowed the identification and inclusion of a more complete combination of behavioural drivers, which were neglected in previous research. In effect, the IAC framework provided the conceptual and theoretical background to the hypotheses tested in the analysis, such as the relative significance of different sets of factors (e.g. expectations about costs and gains versus social pressure). Habit and affect, for instance, were included along with the normally considered variables such as costs for PPE or for healthcare services to heal pesticide-related health effects. Interestingly, the latter were not relevant in the study area, most likely because PPE was often donated by pesticide sellers and producers and because health services are rarely made use of by farmers in the region.

Some relevant factors, deserve being pointed out. Concerning PPE use, the perception of PPE interfering with the work was significantly related to the use of PPE. Interestingly, this occurred differently depending on the piece of PPE considered (e.g. higher correlations were measured with gloves than with facial protection) (Feola and Binder, 2010a).

Some static factors valued also particularly relevant with reference to pesticide use. For example, farmers cultivating a specific variety of potato (Ica Húila), which is relatively vulnerable to pests, but highly required on the market, were less input-effective. Pesticide producers were also influencing pesticide input-effectiveness. In particular, farmers trained by pesticide producers were achieving higher productivity, but were also less input-effective (Feola and Binder, 2010b). 
4.3.2. Integrative approach. The studies also highlighted feedbacks which cross natural and social systems and which also involve the contextual factors (homeostatic loop). For example, farmers who perceived growing pest resistance as an adverse environmental consequence of pesticide use were more likely to apply a higher dosage or to apply more often than those not perceiving such a contextual factor in order to respond to changing environmental conditions (Feola and Binder, 2010b) (Figure 4).

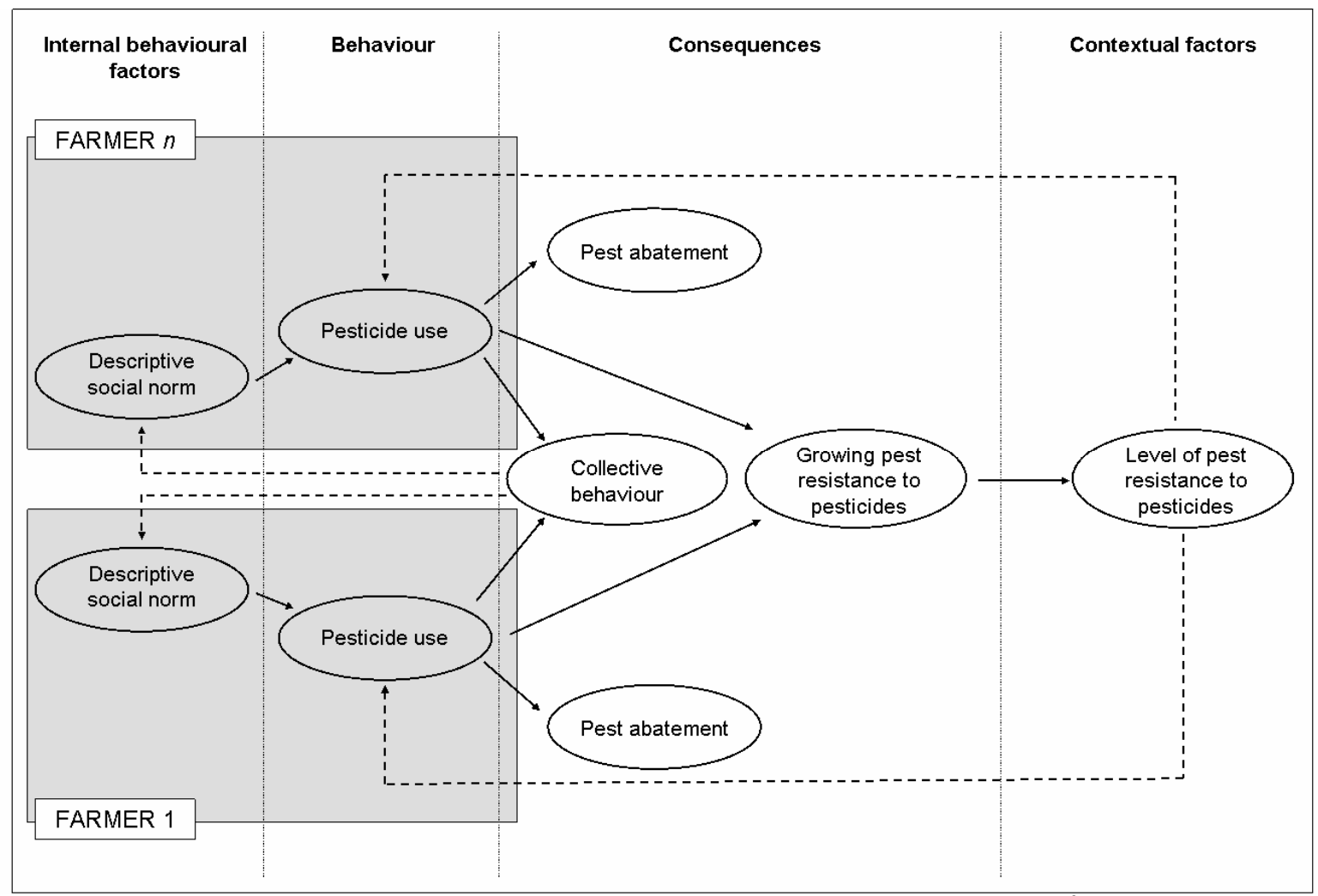

Figure 4. Feedback processes influencing pesticide use in Vereda La Hoya, Colombia. ${ }^{2}$

4.3.3. Feedbacks processes and dynamics. With the framework, feedbacks between consequences of behaviour and internal factors could also be identified, both on individual as well as social level. At individual level, as an example of reflexive self-regulation, the analysis showed how the experience of pesticide-related adverse health effects (i.e. consequences of behaviour) changed PPE use (Feola and Binder, 2010a) (Figure 5). That is, farmers tend to react to pesticide-related adverse health effects by using PPE more frequently. At social level, for instance, the descriptive social norm was relevant for both behaviours investigated. That is, farmers tended to conform to what they perceived as the most frequent behaviour of other farmers, both in terms of PPE and pesticide use, thus reinforcing the social norm (Feola and Binder, 2010a, 2010b) (Figures 4 and 5). Interestingly, such indirect interaction occurring through observation seemed to substitute for direct interactions, especially with respect to PPE use, because health issues are often a taboo and trust among farmers is often an issue in the study region (Baumberger, 2008).

\footnotetext{
${ }^{2}$ Please refer to footnote 2.
} 


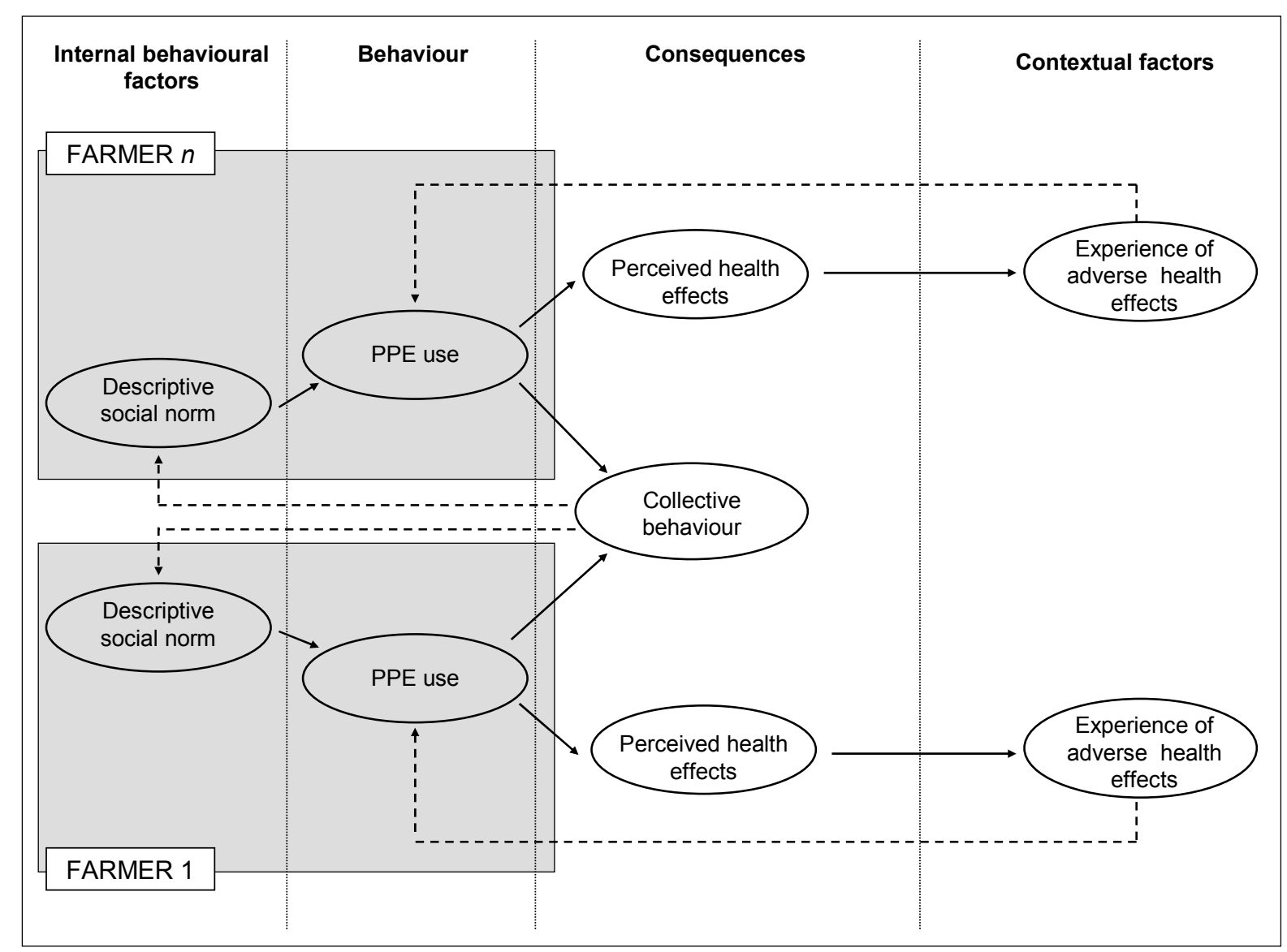

Figure 5. Feedback processes influencing the use of personal protective equipment (PPE) in Vereda La Hoya, Colombia. ${ }^{3}$

\subsection{Policy implications.}

The adoption of the IAC framework permitted an improved understanding of farmers' behaviour and the definition of an articulated policy agenda for triggering a transition towards a more sustainable pesticide use in the agricultural system under study. That is, instead of assuming that the observed unsustainable behaviour was irrational (e.g. not using protective equipment during the application of chemicals), the IAC framework provided an understanding of the action's causes and meaning for the farmers in the specific context in which it took place, that is, the adaptive value of that action (Boudon, 1985 p.69). On such a basis, suggestions for a different, adaptive, policy strategy were given. In particular, the studies challenged the proposition that technological or educational interventions alone might contribute to a transition towards more sustainable agriculture. Instead, the studies pointed out that such a transition is most likely to depend from targeting i) the systemic processes which determine the actual social norms of behaviour and ii) not only farmers, but the interlinkages between actors at the different levels of the agricultural system (e.g. pesticide producers), which is consistent with the understanding of agricultural system as complex social-ecological systems to be managed adaptively (e.g. Darnhofer et al., 2008). In effect, while some influencing factors may be targeted by educational programs (e.g. knowledge about pest resistance to pesticides) or technical solutions (e.g. variety of potato), the most influential

\footnotetext{
${ }^{3}$ Additional factors, which significantly influenced behaviour but which were not involved in feedback processes, are not depicted.
} 
factors have a systemic (e.g. relations between different actors of the agricultural systems) or process nature (e.g. dynamics of social norms reproduction), which calls for more complex intervention strategies.

More specifically, five suggestions were identified to target PPE misuse, i.e. i) diversifying tools (e.g. education, incentives, communication, social control) for different targets (e.g. different pieces of PPE); ii) addressing structural aspects, in particular social norms; iii) sustaining interventions in the long-term; iv) targeting farmers' learning-by-experience on health issues; v) targeting PPE use on a collective level (Feola and Binder, 2010a).

Concerning pesticide misuse, three suggestions were drawn. Intervention strategies need not only to educate farmers, but to change their social and institutional context, by i) involving other agents of the agricultural system such as pesticide producers and sellers; ii) facilitating new institutional settings, i.e. cooperatives; and iii) targeting social dynamics, in particular those related to social norms (Feola and Binder, 2010b).

More details on the policy implications of the two studies and on their convergence with other studies carried out in the area of Boyacá, Colombia, are to be found in Feola and Binder (2010a; 2010b) and (Feola et al., 2010) respectively.

\section{Discussion}

This paper presented the integrative agent-centred (IAC) framework, which fills a gap in the literature by meeting the three main requirements for a research approach to farmers' behaviour in agricultural, social-ecological systems: i) it is grounded in well-established theories which are moreover consistent with the conceptualization of agricultural systems as complex SESs; ii) it provides a flexible and integrative model of human behaviour; iii) it explicitly considers feedback processes between behavioural drivers and in particular between farmers' behaviour and related systems components.

Accordingly, the IAC framework allows for multidimensional and non-constant-cause explanations of farmers' behaviour and focuses on dynamics rather than on states, which makes it appropriate for the investigation of social change (Allen, 1990; Manson, 2001; Scoones et al., 2007). In particular, the IAC framework conceptualizes a structure of feedbacks from external factors to individuals, and may therefore support the investigation of open issues, such as how humans psychologically adapt to the environment (Waring, in press), how social norms influence human agency in complex adaptive systems (Manson, 2001), and how engaging in a behaviour influences attitudes and other behavioural drivers (Edwards-Jones, 2006). Notably, such issues are not only relevant for agricultural systems, but more generally for research on SESs (Scoones et al., 2007). This suggests that the IAC framework, if properly operationalized, can be applied to the analysis of other kinds of individual agents' behaviours taking place in different SESs. Therefore, testing the applicability of the IAC framework to other SES represents a potentially fruitfully direction for further research.

\subsection{The IAC framework's caveats.}

The application of the IAC framework also led to the identification of two caveats. First, when operationalized for a selected behaviour in a specific context, the IAC framework can be rather comprehensive and therefore require intense data inputs. Second, the feedback processes and responses to changing contextual conditions can be better investigated in longitudinal studies. While these conditions might represent a limitation, especially in cases where data or resource availability is low, they also point to some further applications of the framework discussed below.

\subsection{Further applications}


The IAC framework can support and inform a wide range of research designs and methodologies.

First, it can be applied to longitudinal studies. This would allow a better characterization of the feedback processes and their evolution over time. For example, IAC framework-based longitudinal studies can support the identification of thresholds for shifts in individual and collective behaviour (e.g. Scheffer et al., 2003).

Second, the IAC framework can also support diachronically or synchronically comparative studies. The framework is a flexible tool which identifies sets of potentially relevant factors and the structure of their interaction. The specific factors have to be defined agent-, behaviour- and context-specifically and do not all need to be relevant for a behaviour in a certain system. Different combinations of factors may be relevant for different types of agents. Thus, on the basis of the IAC framework, different types of agents can be identified and compared. This would significantly contribute to tracking the population's heterogeneity in agricultural systems, which essentially contributes to their coevolutionary sustainable development (Norgaard, 1984; Gual and Norgaard, in press).

Third, the IAC framework can inform simulation modelling and agent-based modelling in particular, by providing an agent-centred, flexible, and well-grounded model of human behaviour. For example, an IAC framework-based study could provide the understanding of social action which could be validated empirically to inform agent-based models. Thus, agents' behaviour would be based not only on empirical evidence, as suggested by Jager and Janssen (2002), but on a consistent theoretical framework. Similarly, the IAC framework could inform System Dynamics models, where different agent types and the effect of their actions on the overall behaviour of the system could be tested (e.g. Castillo and Saysel, 2005). Fourth, the IAC framework is modular, i.e. each component can constitute a sub-model. Thus, for example, the contextual factors could be broken down into several environmental modules, each corresponding to one environmental compartment or process affected, and in turn potentially affecting, the farmer's practices. In this sense, the IAC framework also provides a structure for integrative modelling and research, which is considered essential for improving understanding and governance of agricultural systems and SES (e.g. Costanza et al., 1993; Folke, 2003).

Finally, a key feature the IAC framework is that it can be implemented through different research methods and combinations of methods. In effect, the data needed to investigate agents' behaviour and micro-macro-level dynamics can be gathered through, for example, lab experiments, which could test the importance of potentially relevant factors and decisionmaking mechanisms; workshops, e.g. to explore the likelihood of selected feedbacks; surveys; qualitative interviews, to investigate selected drivers; and secondary source data, like prices of commodities or meteorological datasets, which would describe some contextual factors. Different methods, i.e. qualitative and quantitative, can therefore be combined, in order to achieve a better understanding and explanation of farmers' behaviour (Boudon, 1985, p. 54).

\section{Conclusions}

The paper presented the integrative agent-centred (IAC) framework, which provides a conceptual structure to investigate farmers' behaviour in agricultural, social-ecological systems.

It was shown how the IAC framework fulfills the three requirements identified by the relevant literature in the field, namely i) being based on an explicit and well-motivated behavioural theory; ii) adopting an integrative approach; iii) including feedback processes and dynamics. Through examples of two applications, it was also shown how the IAC framework can be implemented in a research design to derive policy implications to foster a transition towards more sustainable agricultural practices. 
Finally, further developments and applications of the IAC framework were discussed, which suggest a wide applicability of the framework for investigating, on the one hand, the contribution of individual actions to dynamics in the system and, on the other, the influences of the system on agents' actions. The effectiveness of strategies in fostering sustainability transitions in agricultural systems depends on the understanding of such feedbacks.

\section{Acknowledgments}

The authors are grateful to their colleagues in the Unit for Social and Industrial Ecology at the University of Zurich and to Elena Irwin for their comments on a previous version of this paper and to Heather Murray for English revisions. Sincere thanks go also to Hans-Joachim Mosler and Robert Tobias for their comments on the earliest developments of this research. This research was funded by the Swiss National Science Foundation.

\section{References}

Ajzen, I., 1991. The Theory of Planned Behaviour. Organizational Behaviour and Human Decision Processes, 50:179-211.

Allen, P.M., 1990. Why the future is not what it was. New models of evolution. Futures, 22(6):555-570.

Altieri, M.A., 2002. Agroecology: the science of natural resource management for poor farmers in marginal environments. Agriculture Ecosystems and Environment, 93:1-24.

Archer, M. 1990. Human agency and social structure: a critique of Giddens, in Clark, J., Modgil, C., Modgil, J. (eds.), Anthony Giddens: Consensus and Controversy. Falmer Press, Brighton, UK, pp. 73-84.

Bamberg, S., Schmidt, P., 2003. Incentives, Morality, or Habit? Predicting Students' Car Use for University Routes With the Models of Ajzen, Schwartz, and Triandis. Environment and Behaviour, 35(2):264-285.

Baumberger N., 2008. Exposition, Überzeugungen und Risikoverhalten im Umgang mit Pestiziden: Case study bei Kartoffelnbauern in Vereda La Hoya, Kolumbien. Master Thesis, Ethnologisches Seminar der Universität Zürich

Belcher, K.W., Boehm, M.M., Fulton, M.E., 2004. Agroecosystem sustainability: a system simulation model approach. Agricultural Systems, 79:225-241.

Berger, T., 2001. Agent-based spatial models applied to agriculture: a simulation tool for technology diffusion, resource use changes and policy analysis. Agricultural Economics, 25:245-260.

Berger, T., Schreinemachers, P., Woelcke, J., 2006. Multi-agent simulations for the targeting of development policies in less-favored areas. Agricultural Systems, 88:28-43.

Binder, C.R., Hofer, C., Wiek, A., Scholz, R.W., 2004. Transition towards improved regional wood flows by integrating material flux analysis and agent analysis: the case of Appenzell Ausserrhoden, Switzerland. Ecological Economics, 49:1-17. 
Binder, C.R., 2007. From material flow analysis to material flow management Part II: the role of structural agent analysis. Journal of Cleaner Production, 15(17):1605-1617.

Bolte, J.P., Hulse, D.W., Gregory, S.V., Smith, C., 2006. Modeling biocomplexity - actors, landscapes and alternative futures. Environmental Modelling and Software, 22:570-579.

Boots, R.J., Treolar, C., 2000. Prediction of intern attendance at a seminar-based training programme: a behavioural intention model. Medical Education, 34:512-518.

Boudon, R., 1985. Il posto del disordine. Critica delle teorie del mutamento sociale. Il Mulino, Bologna, pp.284

Braun, A., Jiggins, J., Röling, N., van den Berg, H., Snijders, P., 2006. A Global Survey and Review of Farmer Field School Experiences. Report prepared for the International Livestock Research Institute (ILRI), Wageningen.

Burton, R.J.F., 2004. Reconceptualizing the "behavioural approach" in agricultural studies: a socio-psychological perspective. Journal of Rural studies, 20:359-371.

Castillo, D., Saysel, A.K., 2005. Simulation of common pool resource field experiments: a behavioral model of collective action. Ecological Economics, 55:420-436.

Chaves, B., Riley, J., 2001. Determination of factors influencing integrated pest management adoption in coffee berry borer in Colombian farms. Agriculture Ecosystems and Environment, 87:159-177.

Conway, G. 1998. The doubly green revolution. Cornell University Press, Ithaca, New York, $335 \mathrm{pp}$.

Costanza, R., Wainger, L., Folke, C., Maler, K.-G., 1993. Modeling Complex Ecological Economic Systems. BioScience, 43(8):545-555.

Dahrendorf, R., 2006. Homo Sociologicus. Ein Versuch zur Geschichte, Bedeutung und Kritik der Kategorie der sozialen Rolle. VS Verlag für Sozialwissenschaften, Wiesbaden 2006.

Darnhofer, I., Bellon, S., Dedieu, B., Milestad, R., 2008. Adaptive farming systems - A position paper. Proceedings of the $8^{\text {th }}$ European IFSA Symposium, 6-10 July, ClermontFerrand, France

Dasgupta, S., Meisner, C., Huq, M., 2007. A Pinch or a Pint? Evidence of Pesticide Overuse in Bangladesh. Journal of Agricultural Economics, 58(1):91-114.

Dent, J.B., Edwards-Jones, G., McGregor, M.J., 1995. Simulation of Ecological, Social and Economic Factors in Agricultural Systems. Agricultural Systems, 49:337-351.

Dung, N.H., Dung, T.T.T., 2003. Economic and Health Consequences Of Pesticides Use In Paddy Production In The Mekong Delta, Vietnam. Research Report, International Development Research Centre, Ottawa. 
Edwards-Jones, G., 2006. Modelling farmer decision-making: concepts, progress and challenges. Animal Science, 82:783-790.

FAO (Food and Agriculture Organization of the United Nations), 2002. World agriculture: towards 2015/2030. Earthscan, London.

Feola, G., 2010. Sustainability transition of pesticide use practices: behavioural dynamics and policy options. Doctoral thesis, Faculty of Science, University of Zurich.

Feola, G., Binder, C.R., 2010a. Why don't pesticide applicators protect themselves? Exploring the use of Personal Protecting Equipment among Colombian Smallholders. International Journal of Occupational and Environmental health, 16:11-23.

Feola, G., Binder, C.R., 2010b. Identifying and investigating pesticide application types to promote a more sustainable pesticide use. The case of smallholders in Boyacá, Colombia. Crop Protection, 29:612-622.

Feola, G., Schoell, R., Binder, C.R., 2010. Identifying barriers and opportunities for transitions towards more sustainable agriculture through system analysis. The case of Vereda La Hoya, Colombia. Proceedings of the 9th IFSA Symposium, 4-7 July, Vienna, Austria.

Fishbein, M., Ajzen, I., 1975. Belief, Attitude, Intention, and Behavior: An Introduction to Theory and Research. Addison-Wesley, Reading, M.A.

Folke, C., 2003. Social-Ecological Resilience and Behavioural Responses. In: Biel, A., Hansson, B., Mắrtensson, M., (Editors), Individual and Structural Determinants of Environmental Practice. Ashgate Publishers, London, pp. 226-287.

Fuchs, C., 2003. Structuration Theory and Self-Organization. System Practice and Action Research, 16(2):133-167.

Gagnon, M.-P., Godin, G., Gagné, C., Fortin, J.-P., Lamothe, L., Reinharz, D., Cloutier, A., 2003. An adaptation of the theory of interpersonal behaviour to the study of telemedicine adoption by physicians. International Journal of Medical Informatics, 71:103-115.

Gallino, L., 1993. Dizionario di Sociologia. TEA, Torino

Galt, R.E., 2008. Toward an Integrated Understanding of Pesticide Use Intensity in Costa Rican Vegetable Farming. Human Ecology 36:655-677.

Geels, F.W., Schot, J., 2007. Typology of sociotechnical transition pathways. Research Policy, 36:399-417.

Giddens, A., 1984. The constitution of Society. Polity Press, Cambridge

Gobernación de Boyacá Dirección de Desarrollo Agropecuario, 2004. Acuerdo de competitividad de la cadena agroalimentaria de la papa, para el Departamento de Boyacá, Gobernación de Boyacá Dirección de Desarrollo Agropecuario, Tunja, Colombia.

Gual, M.A., Norgaard, R.B., 2010. Bridging ecological and social systems coevolution: A review and proposal. Ecological Economics, 69(4):707-717. 
Gurung, A.B., 2003. Insects - a mistake in God's creation? Tharu farmers' perception and knowledge of insects: A case study of Gobardiha Village Development Committee, DangDeukhuri, Nepal. Agriculture and Human Values, 20:337-370.

Happe, K., Kellermann, K., Balmann, A., 2006. Agent-based analysis of agricultural policies: an illustration of the agricultural policy simulator AgriPoliS, its adaptation, and behaviour. Ecology and Society, 11(1):49.

Heong, K.L., Escalada, M.M., 1999. Quantifying farmers' pest management decisions: beliefs and subjective norms in stem borer control. Crop Protection, 18:315-322.

Heong, K.L., Escalada, M.M., Sengsoulivong, V., Schiller, J., 2002. Insects amanagement beliefs and practices of rice farmers in Laos. Agriculture Ecosystems and Environment, 92:137-145.

Irwin, E., Geoghean, J., 2001. Theory, data, methods: developing spatially explicit economic models of land use change. Agriculture Ecosystems and Environment, 85:7-23.

Kahnemann, D., Tversky, A., (Editors), 2000. Choice, Values, and Frames. Cambridge University Press, New York.

Krebs, F., Elbers, M., Ernst, A., 2007. Modelling social and economic influences on the decision making of farmers in the Odra region. Paper presented at the 4th European Social Simulation Association, Toulose.

Jackson, T., 2004. Motivating Sustainable Consumption. A review of evidence on consumer behaviour and behavioural change. A report to the Sustainable Development Research Network. Centre for Environmental Strategy, University of Surrey, Guilford.

Jager, W., Janssen, M., 2002. The Need for and Development of Behaviourally Realistic Agents. In: Sichman, J.S., Bousquet, F., Davidsson, B., (Editors). Multi-Agent-Based Simulation II. Third International Workshop, MABS, Bologna Italy July 2002. Springer Verlag, Berlin Heidelberg.

Janssen, M.A., Jager, W., (Editors), 2000. The human actor in ecological-economic models. Special issue. Ecological Economics, 35.

Janssen, M.A., Ostrom, E., 2006. Governing Social-Ecological Systems. In: Tesfatsion, L., Judd, K.L., (Editors), Handbook of Computational Economics, Volume 2. Elsevier, Amsterdam, pp. 1465-1509.

Leach, M., Bloom, G., Ely, A., Nightingale, P., Scoones, I., Shah, E., Smith, A., 2007. Understanding Governance: pathways to sustainability, STEPS Working Paper 2, STEPS Centre, Brighton.

Lichtemberg, E., Zimmerman, R., 1999. Adverse Health Experiences, Environmental Attitudes, and Pesticide Usage Behaviour of Farm Operators. Risk Analysis, 19(2):283-294.

Liu, J., 2001. Integrating ecology with human demography, behavior, and socioeconomics: Needs and approaches. Ecological Modelling, 140;1-8. 
Liu, J., Dietz, T., Carpenter, S.R., Alberti, M., Folke, C., Moran, E., Pell, A.N., Deadman, P., Kratz, T., Lubchenko, J., Ostrom, E., Ouyang, Z., Provencher, W., Redman, C.L., Schneider, S.H., Taylor, W.W., 2007. Complexity of Coupled Human and Natural Systems. Science, 317:1513-1516.

Manson, S.M., 2001. Simplifying complexity: a review of complexity theory. Geoforum, $32: 405-414$.

Mayumi, K., Giampietro, M., 2006. The epistemological challenge of self-modifying systems: Governance and sustainability in the post-normal science era. Ecological Economics, 57:382399.

Matthews, R., Selman, P., 2006. Landscape as a Focus for Integrating Human and Environmental Processes. Journal of Agricultural Economics, 57(2):199-212.

McGregor, M.J., Rola-Rubzen, M.F., Murray-Prior, R., 2001. Micro and macro-level approaches to modelling decision making. Agricultural Systems, 69:63-83.

Merot, A., Bergez, J.-E., Capillon, A., Wery, J., 2008. Analysing farming practices to develop a numerical, operational model of farmers' decision-making processes: An irrigated hay cropping system in France. Agricultural Systems, 98:108-118.

Munro, A., 1997. Economics and biological evolution. Environmental and Resource Economics, 9:429-449.

Nkamleu, G.B., Adesina, A.A., 2002. Determinants of chemical input use in peri-urban lowland systems: bivariate probit analysis in Cameroon. Agricultural Systems, 63:111-121.

Noailly, J., 2008. Co-evolution of economic and ecological systems. An application to agricultural pesticide resistance. Journal of Evolutionary Economics 18:1-29.

Norgaard, R.B., 1984. Coevolutionary Agricultural Development. Economic Development and Cultural Change, 32(3):525-546.

Öhlmér, B., Olson, K., Brehmer, B., 1998. Understanding farmers' decision making processes and improving managerial assistance. Agricultural Economics, 18:273-290.

Oriade, C.A., Dillon, C.R., 1997. Developments in biophysical and bioeconomic simulation of agricultural systems: a review. Agricultural Economics, 17:45-58.

Ospina, J.M., Manrique, F.G., Ariza, N.E., 2008. Salud, ambiente y trabajo en poblaciones vulnerables: los cultivadores de papa en el centro de Boyacá, Revista de la Facultad Nacional de Salud Publica 26(2):143-152.

Ostrom, E., Janssen, M.A., Anderies, J.M., 2007. Going beyond panaceas. Proceedings of the National Academy of Sciences, 104(39):15176-15178.

Palis, F.G., Flor, R.J., Warburton, H., Hossain, M., 2006. Our farmers at risk: behaviour and belief system in pesticide safety. Journal of Public Health. 28(1):43-48. 
Park, J., Seaton, R.A.F., 1996. Integrative Research and Sustainable Agriculture. Agricultural Systems, 50:81-100.

Parker, D.C., Berger, T., Manson, S.M. (Editors), 2001. Agent-Based Models of Land Use and Land Cover Change. Report and Review of an International Workshop, October 4-7, 2001, LUCC International Project Office, Louvain.

Peterson, G., 2000. Political ecology and ecological resilience: An integration of human and ecological dynamics. Ecological Economics, 35:323-336.

Rabin, M., 1998. Psychology and Economics. Journal of Economic Literature, 36(1):11-46.

Rahman, S. 2003. Farm-level pesticides use in Bangladesh: determinants and awareness. Agriculture Ecosystems \& Environment 95:241-252.

Rammel, C., Hinterberger, F., Bechtold, U., 2004. Governing Sustainable Development. A co-evolutionary perspective on transitions and change. GOSD Working Paper No.1. Institute of Anthropology, University of Vienna, Vienna.

Rammel, C., Stagl, S., Wilfing, H., 2007. Managing complex adaptive systems - a coevolutionary perspective on natural resource management. Ecological Economics, 63:9-21.

Redman, C.L., Grove, J.M., Kuby, L.H., 2004. Integrating Social Science into Long-Term Ecological Research (LTER) Network: Social Dimensions of Ecological Change and Ecological Dimensions of Social Change. Ecosystems, 7:161-171.

Rigby, D., Caceres, D., 1997. The Sustainability of Agricultural Systems. Working Paper No. 10, Institute for Development Policy and Management, University of Manchester; Manchester.

Rossing, W.A.H., Zander, P., Josien, E., Groot, J.C.J., Meyer, B.C., Knierim, A., 2007. Integrative modeling approaches for analysis of impact of multifunctional agriculture: A review for France, Germany and the Netherlands. Agriculture Ecosystem and Environment 120:41-57.

Rotmans J., Kemp, R., van Asselt M., 2001. More evolution than revolution: transition management in public policy. Foresight, 3(1):1-17.

Ruttan, V.W., 1999. The transition to agricultural sustainability. Proceeding of the National Academy of Sciences, 96:5960-5967.

Scheffer, M., Westley, F., Brock, W., 2003. Slow Response of Societies to New Problems: Causes and Costs. Ecosystems, 6:493-502.

Schmit, C., Rounsevell, M.D.A., 2006. Are agricultural land use patterns influenced by farmer imitation? Agriculture Ecosystems and Environment, 115:113-127.

Schöll, R., Binder, C.R., 2009. System Perspectives of Experts and Farmers Regarding the Role of Livelihood Assets in Risk Perception: Results from the Structured Mental Model Approach. Risk Analysis, 29(2):205-222. 
Scoones, I., 1999. New Ecology and the Social Sciences: What Prospects for a Fruitful Engagement? Annual Review of Anthropology, 28:479-507.

Scoones, I., Leach, M., Smith, A., Stagl, S., Stirling, A. and Thompson, J., 2007. Dynamic Systems and the Challenge of Sustainability, STEPS Working Paper 1, STEPS Centre, Brighton.

Sharma, T., Carmichael, J., Klinkenberg, B., 2006. Integrated modelling for exploring sustainable agriculture futures. Futures, 38:93-113.

Smith, A., Stirling, A., 2008. Social-ecological resilience and sociotechnical transitions: critical issues for sustainability governance, STEPS Working Paper 8, STEPS Centre, Brighton.

Tait, J., Morris, D., 2000. Sustainable development of agricultural systems: competing objectives and critical limits. Futures, 32:247-260.

Thompson, R.L., Higgins, C.A., Howell, J.M., 1991. Personal Computing: Toward a Conceptual Model of Utilization. MIS Quarterly, 15(1):125-143.

Thompson, J., Millstone, E., Scoones, I., Ely, A., Marshall, F., Shah, E.and Stagl, S., 2007. Agri-food System Dynamics: pathways to sustainability in an era of uncertainty. STEPS Working Paper 4, STEPS Centre, Brighton.

Triandis, H.C., 1980. Values, Attitudes and Interpersonal Behavior. Nebraska Symposium on Motivation, University of Nebraska Press, Lincoln/London.

UNCED (United Nation Conference on Environment and Development), 1992. Agenda 21 an action plan for the next century. Endorsed at the United Nations Conference on Environment and Development, New York.

van den Bergh, J.C.J.M., Ferrer-i-Carbonell, A., Munda, G., 2000. Alternative models of individual behaviour and implications for environmental policy. Ecological Economics, $32: 43-61$.

Waichmann, A.V., Eve, E., da Silva Nina, N.C., 2007. Do farmers understand the information displayed on pesticide product labels? A key question to reduce pesticides exposure and risk of poisoning in the Brazilian Amazon. Crop Protection, 26:576-583.

Waring, T.M., 2010. New evolutionary foundations: Theoretical requirements for a science of sustainability. Ecological Economics, 69(4):718-730.

Weber, M. 1978. Economy and Society: An Outline of Interpretive Sociology, vol. I. University of California Press, Berkeley.

Webster, P., 1999. The challenge of Sustainability at the Farm Level: Presidential Address. Journal of Agricultural Economics, 50(3):371-387.

Willock, J., Deary, I.J., Edwards-Jones, G., Gibson, G.J., McGregor, M.J., Sutherland, A., Dent, J.B., Morgan, O., Grieve, R., 1999. The Role of Attitudes and Objectives in Farmer 
Decision Making: Business and Environmentally-Oriented Behaviour in Scotland. Journal of Agricultural Economics, 50(2):286-303.

Woodhill, J., Röling, N.S., 1998. The second wing of the eagle: the human dimension in lerning our way to more sustainable futures. In Röling, N.G., Wagemakers, M.A.E. (Eds.), Facilitating Sustainable Agriculture. Cambridge University Press, Cambridge, UK, 46-72.

WSSD (World Summit on Sustainable Development), 2002. Report of the World Summit on Sustainable Development. Johannesburg.

Zubair, M., Garforth, C., 2006. Farm level tree planting in Pakistan: the role of farmers' perceptions and attitudes. Agroforestry Systems, 66:217-229. 